\title{
A ordem metodológica do círculo de Bakhtin para o estudo da língua: uma análise do gênero poema
} \author{
analysis of the genre poem \\ Leliane Regina Ortega ${ }^{1}$ \\ Universidade Estadual do Oeste do Paraná \\ Marcelo Nicomedes dos Reis Silva Filho \\ Universidade Federal do Maranhão
}

The methodological order of the Bakhtin circle for the language study: an

\begin{abstract}
- RESUMO: Os estudos do Círculo de Bakhtin fornecem ancoragem para o trabalho com a língua concreta e viva na sala de aula. A partir dessas concepções teóricas, amparamo-nos na "[...] ordem metodológica para o estudo da língua" (BAKHTIN/VOLOCHÍNOV, 2009[1929]) e desenvolvemos um procedimento didático com o gênero do discurso poema. No presente artigo, refletimos sobre o resultado dessas ações, ou seja, o que os textos dos alunos revelam sobre essa forma de atuação didática. Destarte, o objetivo é analisar como os elementos constitutivos do gênero - conteúdo temático, estilo e construção composicional se configuraram nas produções escritas. A metodologia consiste em um estudo de caso para a geração de dados, no qual o texto de um aluno é analisado representando as produções textuais de toda a turma. O aporte teórico sustenta-se em Bakhtin (2010[1979]), Bakhtin/Volochínov (2009[1929]) e Volochínov/Bakhtin (1926). Os resultados demonstram que ações didáticas embasadas na Concepção Dialógica da Linguagem podem ser vislumbradas, por meio dos elementos constitutivos, nas elaborações dos alunos.
\end{abstract}

- PALAVRAS-ChAVE: Gênero discursivo poema; Ordem Metodológica; Ensino de Língua Materna.

- ABSTRACT: The studies of Bakhtin Circle can contribute to the concrete and living language teaching. From these theoretical concepts, we admitted them in the "[...] methodological for the study of language" (Bakhtin / Volochínov, 2009 [1929]) and developed a didactic procedure with the genre of the speech poem. Thus, the objective is to analyze how the constitutive elements of the genre - thematic content, style and compositional construction - are configured in the written productions. The methodology consists of a case study for data generation, in which a student's text is analyzed representing the textual productions of the entire class. we were theoretically supported by Bakhtin (2010 [1979]), Bakhtin/Volochinov (2009 [1929]) and Volochinov/Bakhtin (1926). The results show that, didactic actions based on the Dialogical Conception of Language can be glimpsed, through the constitutive elements, in the students' elaborations.

- KEYWORDS: Discursive genre poem; methodological order; mother tongue teaching.

\footnotetext{
${ }^{1}$ Mestre em Letras - Linguagem e Sociedade pelo PPGL - Universidade Estadual do Oeste do Paraná - Unioeste, e professora da Rede Púbica de Ensino do Estado do Paraná. E-mail: leliortega@gmail.com.

${ }^{2}$ Mestre em Educação pelo PPGE - Universidade Católica de Brasília - UCB, bolsista da Fundação de Amparo da Pesquisa do Maranhão - FAPEMA e Professor na Universidade Federal do Maranhão - UFMA, Campus São Bernardo. E-mail: marcelo.nicomedes@ufma.br.
} 


\section{Introdução}

Os estudos dos pesquisadores que compõem o Círculo de Bakhtin demonstram que o discurso verbal origina-se em uma situação extralinguística que está associada à vida. A construção do enunciado ultrapassa os aspectos fonéticos, morfológicos, semânticos e, até mesmo, a entonação, uma vez que é engendrado por uma situação extraverbal, com a qual mantém estreita e necessária relação. Nessa proposição, a linguagem ancora-se em um contexto social, histórico e ideológico e, assim, para estudá-la, segundo Bakhtin/Volochinov (2009[1929]), é necessário reconhecer os elementos constitutivos que situam o enunciado no espaço social e histórico.

Compreender essas afirmações e deslocá-las para o ensino significa assumir uma postura discursiva pautada na interação verbal, a qual, segundo Bakhtin/Volochínov (2009[1929], p. 127), "constitui a realidade fundamental da língua”. Nessa direção, não seria possível estudar o gênero fora de sua existência ideológica, cultural e social.

Para a elaboração de um procedimento didático, Bakhtin/Volochínov (2009[1929]) e Bakhtin (2010[1979]) apresentam orientações para o estudo da língua que denominam como ordem metodológica. Além do contexto extraverbal, três princípios básicos emolduram o estudo de dado gênero do discurso: o conteúdo temático, o estilo e a construção composicional.

No que tange a esse aspecto, o presente artigo tem como base teórica os estudos do Círculo de Bakhtin e tem o objetivo de refletir sobre como os elementos constitutivos do gênero configuram-se no texto produzido por alunos do primeira série do Ensino Médio após um procedimento de ensino construindo nessas bases teóricas.

Em razão das delimitações estruturais de um artigo, optou-se pelo estudo de caso para a geração de dados, uma vez que, "o estudo de caso parte do princípio de que o leitor vá usar esse conhecimento tácito para fazer as generalizações e desenvolver novas ideias, novos significados, novas compreensões" (LÜDKE; ANDRÉ, 2014, p. 27). Assim, o texto de um aluno foi analisado qualitativamente a fim de demonstrar os aspectos correntes nos textos de toda a turma e, por conseguinte, evidenciar ou refutar a eficácia da prática pedagógica adotada. Consideramos que o estudo de caso qualitativo "[...] oferece elementos preciosos para uma melhor compreensão do papel da escola e suas relações com outras instituições da sociedade" (LÜDKE; ANDRÉ, 2014, p. 28).

Dentre as justificativas possíveis para se conduzir as ações didáticas em sala de aula, destacamos três: i) tal percurso metodológico, como já acenado nos parágrafos anteriores, de fato reconhece a natureza interativa e dialógica da linguagem; isto é, parte dos modos como os sujeitos, em determinados contextos sociais e históricos, organizam seus enunciados e os fazem circular na sociedade; ii) os documentos oficiais, da instância federal à municipal, na maioria das vezes, se fundamentam a partir desses estudos, sendo, então, importante que conheçamos essas reflexões teóricas; iii) grande parte dos materiais didáticos à disposição dos professores mencionam as correntes teóricas citadas nesse artigo, contudo, conforme delineia Rojo (2013, p. 164),“embora busquem se adequar a referenciais e propostas curriculares mais recentes, mantêm-se ligados a certa 'tradição' na abordagem de seus objetos de ensino", priorizando uma conduta formal com as normas linguísticas, afastando-se das variedades sociais e geográficas de interações verbais.

A intenção, a princípio, era focalizar a prática discursiva de leitura, mas os próprios alunos sugeriram que chegássemos à produção escrita e que seus textos fossem publicados em um Blog criado e divulgado por eles.

Para apresentarmos o todo dessa atividade, assim organizamos o artigo: primeiramente, apresentamos algumas reflexões sobre o conceito de gênero discursivo e 
seus elementos constitutivos; em seguida, discutimos sobre o gênero poema, relacionando-o com a orientação metodológica bakhtiniana para o estudo da língua; e, finalmente, apresentamos algumas reflexões sobre como um procedimento de ensino baseado nesses pressupostos configura-se no texto do aluno.

\section{Pressupostos teóricos}

Para os estudiosos do Círculo de Bakhtin, a enunciação efetiva-se por meio da interação verbal e desenvolve-se nas relações sociais, visto que, segundo Volochínov (2013[1930], p. 157), “a língua não é de modo algum um produto morto, petrificado, da vida social: ela se move continuamente e seu desenvolvimento segue aquele da vida social". Assim, a língua é viva e se adapta às diferentes realidades de interação, uma vez que, "uma enunciação concreta nasce, vive e morre no processo de interação social dos participantes da enunciação" (VOLOCHÍNOV, 2013[1930], p. 86).

O enunciado é situado no "chão real" e não possui nenhum sentido desvinculado da situação de interação, ou seja, distante do real não pode mais ser enunciado, apenas palavras abstratas, mortas em sua significação discursiva. Logo, o enunciado para existir absorve os elementos linguísticos e a situação social.

Nessa perspectiva, a interação por meio da linguagem requer a existência de interlocutores, uma vez que "a enunciação é produto da interação de dois indivíduos socialmente organizados" (BAKHTIN/VOLOCHÍNOV, 2009[1929], p. 127); em vista disso, sem interlocutores não há enunciação. Além disso, os estudiosos do Círculo exploram a conotação social da linguagem e a concebem como "produto da atividade humana coletiva" (VOLOCHÍNOV, 2013[1930], p. 141), que transcende a materialidade linguística e se concretiza em discursos. Em uma situação de interação específica, o enunciado absorve o objeto comunicativo e concede-lhe um sentido absoluto, submete-se ao projeto de dizer do locutor e expressa essa vontade discursiva ao interlocutor, além de manifestar-se em formas singulares de acordo com a esfera de atividade humana que o provoca. Porquanto, o locutor seleciona um gênero do discurso que melhor concretiza seu projeto enunciativo.

\subsection{Gênero do discurso}

Os gêneros do discurso são elaborados pelos diversos campos de atividade humana e nos apropriamos deles quando iniciamos a aprendizagem da língua materna oral, logo, estão ancorados em um contexto social, histórico e ideológico, uma vez que "a realidade do gênero é a realidade social de sua realização no processo de comunicação social” (MEDVIÉDEV, 2012[1928], p. 200).

$\mathrm{O}$ enunciado toma a forma de um gênero para se adaptar à situação de interação e apenas em seu uso real apreendemos a língua. Isso inclui desde os diálogos mais simples até as formas mais complexas de interação, como, por exemplo, as manifestações científicas e os gêneros literários. Assim sendo, os gêneros estão presentes em todas as nossas relações sociais formais e informais, ou seja, "[...] são correias de transmissão entre a história da sociedade e a história da linguagem" (BAKHTIN, 2010[1979], p. 268).

No que tange a esse aspecto, os gêneros do discurso, com sua estabilidade relativa, nascem de uma necessidade social de dizer e obedecem a certas estruturas moldadas pela repetição histórica que os ajustam a campos específicos da atividade 
humana. Os gêneros não podem ser desvinculados desses campos, pois eles os antecedem, e ignorá-los tornaria sua compreensão superficial, dado que os gêneros se originam em diferentes campos de atividade humana, a partir de uma necessidade real de dizer, isso faz com que apresentem características próprias influenciadas pelas especificidades de cada campo.

Posto isso, Sobral (2009) apresenta um resumo das principais características do gênero em consonância com as concepções do Círculo:

1. "O gênero mobiliza, mediante o discurso, formas textuais, mas não é mobilizado por elas" (SOBRAL, 2009, p. 131), haja vista, os elementos linguísticos são incitados pela necessidade de interlocução do gênero, mas não são suficientes para a compreensão do texto, pois representam apenas o aspecto material, que não é capaz de definir ou modificar o gênero.

2. "O discurso é o espaço em que são mobilizadas as textualidades" (SOBRAL, 2009, p. 131), pois as marcas textuais são selecionadas pelo campo do discurso.

3. "O texto [...] é o espaço de escolha dos recursos linguísticos e estilísticos, que depende da relação enunciativa" (SOBRAL, 2009, p. 131)

assim a enunciação determina os recursos linguísticos e estilísticos que se materializam no texto e a escolha desses elementos depende da situação de interação e dos interlocutores.

4. "As formas textuais apontam para o(s) gênero(s) que as mobilizam costumeiramente e, por isso, ao escolher um gênero, costumamos evocar a(s) forma(s) textual(ais) típica(s) desse gênero" (SOBRAL, 2009, p. 131), logo, os recursos linguísticos acabam repetindo-se em textos do mesmo gênero, por isso, são acionados pela escolha do gênero, entretanto, podem ser modificados, já que é o gênero que lhe atribui sentido.

5. "A escolha do gênero do discurso depende da relação específica entre os interlocutores nos termos da esfera de atividades" (SOBRAL, 2009, p. 131), o que faz com que a relação entre os interlocutores determine a escolha do gênero que pode transportar o enunciado.

6. "A inserção genérica do discurso determina a escolha da forma textual, que, por conseguinte, pode variar no interior de um mesmo gênero sem por isso alterá-lo substancialmente, dado que é o gênero e o discurso que lhe atribuem sentido" (SOBRAL, 2009, p. 131), consequentemente, o gênero atribui sentido aos aspectos textuais e não o contrário.

Cada situação discursiva exige um gênero específico. Logo, ao organizamos nossos enunciados, devemos considerar o lugar de onde estamos falando/escrevendo, pois, cada situação pressupõe elementos particulares e cada esfera possui finalidades que lhe são próprias. Esses aspectos determinam a substância temática do texto, o estilo da linguagem a ser empregada e a construção composicional na qual deve configurar-se aquele enunciado. Os estudos do Círculo de Bakhtin não se voltaram para a didática da sala de aula; porém, é possível encontrar uma ordem metodológica para o estudo da língua em Bakhtin/Volochínov (2009[1979]), assim especificada: 
A língua vive e evolui historicamente na comunicação verbal concreta, não no sistema linguístico abstrato das formas da língua nem no psiquismo individual dos falantes.

Disso decorre que a ordem metodológica para o estudo da língua deve ser o seguinte:

1. As formas e os tipos de interação verbal em ligação com as condições concretas em que se realiza.

2. As formas das distintas enunciações, dos atos de fala isolados, em ligação estreita com a interação de que constituem os elementos, isto é, as categorias de atos de fala na vida e na criação ideológica que se prestam a uma determinação pela interação verbal.

3. A partir daí, exame das formas da língua na sua interpretação linguística habitual (BAKHTIN/VOLOCHÍNOV, 2009[1929], p. 129).

Essa mesma orientação foi retomada por Bakhtin (2010[1979]), quando aponta o conteúdo temático, o estilo e a construção composicional como os elementos que constituem a dimensão verbal do gênero do discurso. Assim, em uma situação didática de ensino da língua, estudar um gênero significa reconhecer nele esses elementos associados ao contexto extraverbal.

O tema é sempre único e irrepetível e expressa a situação sócio-histórica da interação, pois segundo Bakhtin/Volochínov (2009[1929], p. 136-137), “só a compreensão ativa nos permite apreender o tema". Então, esse elemento vincula-se à situação extraverbal que suscita o enunciado, visto que "[...] caracteriza-se por atribuir uma apreensão delimitadora do objeto do sentido e por compor-se de uma expressão valorativa, uma vez que não há neutralidade no domínio do enunciado" (GRILLO, 2014, p.146).

O conteúdo temático contempla o contexto de produção, o momento histórico, os interlocutores, a esfera e outros elementos que ultrapassam a significação, pois "participam da construção do tema não apenas os elementos estáveis da significação, mas também os elementos extraverbais, que integram a situação de produção, de recepção e de circulação" (CEREJA, 2013, p. 202). Por isso, adquire uma conotação singular, posto que se insere na finalidade discursiva de um sujeito dentro de uma prática social que, de acordo com Costa-Hübes (2014, p. 24), "atua nos gêneros para situá-los nas situações interativas, representando as diferentes formas de conceber a realidade" e refere-se à forma como o gênero discursivo seleciona os elementos da realidade para a construção do enunciado.

O estilo é constituído pelas marcas linguísticas, enunciativas e discursivas que determinam as escolhas lexicais e morfossintáticas que constroem o texto. E ainda, é o elemento que permite a expressão individual do autor, segundo Brait (2013, p. 86), "como sendo a relação do autor com a língua e, consequentemente, sua forma de utilização da língua". Dentro das fronteiras estabelecidas pelo gênero, o autor utiliza estratégias específicas para elucidar seu projeto de dizer. Então, o estilo considera o interlocutor, reflete, nas escolhas linguísticas, a esfera de circulação e situa-se no campo das relações dialógicas, por isso, de acordo com Bakhtin (2010[1979], p. 266), “é indissociável de determinadas unidades temáticas e de determinadas unidades composicionais", por isso, reflete a forma de ser da linguagem e a relação entre os interlocutores.

A construção composicional evidencia-se pelas características específicas que identificam o gênero. Assim sendo, construções diferenciadas, mas nem sempre estáveis, possibilitam ao interlocutor identificar o gênero mesmo antes da leitura 
integral do texto, em alguns casos. Cada gênero possui elementos composicionais que o diferencia dos demais e o insere em uma determinada esfera, revelando o tipo de relação entre os interlocutores. Assim sendo, a construção composicional, de acordo com Bakhtin (2010[1979], p. 300), consiste na "forma padrão relativamente estável de estruturação de um todo", trata-se do elemento que mais apresenta regularidades, pois organiza o enunciado permitindo ao sujeito identificar o gênero ao qual pertence determinado texto.

De acordo com os pressupostos teóricos apresentados, a "vontade discursiva" do locutor e a esfera de atividade humana determinam o gênero mais apropriado para dar forma ao enunciado e garantir o processo de interlocução. Dessa forma, se reconhecermos os gêneros discursivos como importantes instrumentos para 0 aprimoramento da linguagem, cumpre-nos assumir uma postura discursiva no ensino de Língua Portuguesa que privilegie a ampliação do domínio das práticas discursivas, por meio do trabalho com gêneros e com seus elementos constitutivos materializados em situações reais de comunicação, contemplando a escrita como uma forma de interação que deve ser privilegiada no contexto escolar.

Cada gênero do discurso possui especificidades como observamos na próxima subseção sobre o gênero poema.

\section{0 gênero discursivo poema}

O gênero poema versa sobre a imaginação, a criatividade, mas também, está no mundo real fazendo ecoar vozes que habitam o mundo do autor-poeta. E assim, também revela jogos ideológicos, ou seja, deixa transparecer os enfrentamentos sociais. De acordo com Volochínov/Bakhtin, a comunicação estética caracteriza-se pelo fato de ser

[...] totalmente absorvida na criação de uma obra de arte, e nas suas contínuas recriações por meio da co-criação dos contempladores, e não requer nenhum outro tipo de objetivação. Mas, desnecessário dizer, esta forma única de comunicação não existe isoladamente; ela participa do fluxo unitário da vida social, ela reflete a base econômica comum, e ela se envolve em interação e troca com outras formas de comunicação (VOLOCHÍNOV/BAKHTIN, 1926, p. 4).

Compreendemos que o poeta mobiliza processos interacionais; o que faz com que a palavra poética tem uma existência social. O poema "inventa" um mundo, mas que, na verdade, representa mundos existentes, seja ele incorporado por dores, por indignações ou por singelezas. Assim sendo, os poemas constituem enunciações concretas e contextualizadas nas quais pairam relações dialógicas e avaliações sociais.

Por outro lado, o poeta concede expressividade às palavras, pois possui uma intenção discursiva específica; desse modo, embora as palavras selecionadas pelo autor sejam permeadas pelo meio social, ele lhe concede uma organização nova por meio da "relação subjetiva emocionalmente valorativa do falante com o conteúdo do objeto e do sentido do enunciado" (BAKHTIN, 2010[1979], p. 289). Então, não existe enunciado neutro; o elemento expressivo ajuda a determinar as escolhas linguísticas/enunciativas do locutor. Segundo Volochínov/Bakhtin (1926, p. 12), 
O poeta, afinal, seleciona palavras não no dicionário, mas do contexto da vida onde as palavras foram embebidas e se impregnaram de julgamentos de valor. Assim, ele seleciona os julgamentos de valor associados com as palavras e faz isso, além do mais, do ponto de vista dos próprios portadores desses julgamentos de valor. Pode-se dizer que o poeta trabalha constantemente em conjunção com a simpatia ou antipatia, com a concordância ou discordância de seus ouvintes. Além disso, a avaliação opera também em relação ao objeto do enunciado o herói.

Compreendemos que o autor/poeta considera seu interlocutor ao produzir o poema, portanto, seu texto apresenta julgamentos valorativos, sejam do autor ou vinculados às práticas sociais que atribuem diferentes avaliações à carga semântica das palavras.

A teoria mobilizada pelos estudiosos do Círculo de Bakhtin não traçou plano para a didatização do gênero, mas apresentou a ordem metodológica (BAKHTIN/VOLOCHÍNOV, 2009[1929]) para o estudo da língua. Por isso, propomos a abordagem do gênero poema por meio de um procedimento didático estruturado a partir dessa base teórica, uma vez que, segundo Volochínov/Bakhtin (1926, p. 18), "o poeta adquire suas palavras e aprende a entoá-las ao longo do curso de sua vida inteira no processo do seu contato multifacetado com seu ambiente", haja vista que, mesmo tratando-se de um gênero literário, traz à tona a ideologia do cotidiano; contudo, com o diferencial de explorar o encanto das palavras de forma plussignificativa. Refletiremos sobre isso na próxima subseção.

\subsection{A ordem metodológica para o estudo da língua no gênero poema}

Consideramos que o estudo de qualquer gênero do discurso deve partir do reconhecimento de que se trata de uma prática social de uso da linguagem organizada para um fim específico, assim, extrapola o plano linguístico e absorve a situação extraverbal.

Em se tratando do poema, é oportuno reconhecer que o sujeito que produz, apesar da subjetividade aparente, assume um papel social, uma vez que se insere em uma prática social de uso da língua, que lhe impõe algumas exigências sobre a organização de seu discurso, por isso, para adentrar a discursividade do gênero é preciso analisar o contexto social, histórico e ideológico que o envolve, a esfera de produção e circulação, seu conteúdo temático, seu estilo e sua construção composicional. Ao organizar seu enunciado, o poeta estabelece diálogo com outros que o antecedem, sem deixar de pressupor outros que o sucederão.

Nessa perspectiva, analisamos diversos poemas na sala de aula para o trabalho didático com esse gênero. Um dos selecionados para o trabalho foi o texto $O$ menino que carregava água na peneira ${ }^{3}$ (1999), de Manoel de Barros.

Por meio de reflexões orais e escritas, exploramos os elementos constitutivos do gênero poema nesse texto e em outros, em consonância com o contexto de produção. Embora, estabelecer regularidades em um gênero literário tão subjetivo não seja tarefa fácil, tentamos refletir sobre como se organizam os elementos nesse exemplar do gênero, uma vez que consideramos de fundamental importância estabelecer um caminho para seu estudo no espaço escolar.

3 Disponível em http://www.ihu.unisinos.br/43-noticias/oracoes-inter-religiosas-ilustradas/593156-o-menino-quecarregava-agua-na-peneira-manoel-de-barros-na-oracao-inter-religiosa-desta-semana Acesso em 17/jun/2019 
Nosso procedimento didático partiu da reflexão sobre práticas sociais de uso da linguagem que envolve a leitura e a escrita do gênero poema. Buscamos desenvolver estratégias no sentido de reconhecer o gênero e a sua finalidade por meio de leitura em livros e blogs para, posteriormente, explorar os elementos constitutivos.

Partindo do pressuposto de que o conteúdo temático organiza o projeto de dizer do autor, buscamos estimular os alunos a refletirem e se posicionarem sobre o fato que pode ter impulsionado o poeta a produzir esse texto voltado para o universo infantil.

Além disso, incentivamos os alunos a buscarem o tema do texto e analisarem a relação do tema com a vida cotidiana, ou seja, com o contexto de produção e, ainda, estabelecer um posicionamento sobre o tema, apresentando uma resposta a partir dessa leitura. Para isso, buscamos desenvolver uma pesquisa sobre o autor do texto, seus objetivos ao produzir esse texto e possíveis interlocutores, o local de circulação e o contexto histórico e pessoal de produção.

O contexto de produção foi explorado por meio de questionamentos como: quem produziu; quando e onde foi publicado; para que interlocutor; com que propósito discursivo; qual o posicionamento valorativo dos interlocutores dentre outros questionamentos.

O autor Manoel de Barros narra subjetivamente, nesse poema, sua infância. De acordo com a Fundação Manoel de Barros ${ }^{4}$, o autor nasceu em 19 de dezembro de 1916, em Cuiabá (MT), mas viveu no Rio de Janeiro, em Nova York, Paris, Itália e Portugal. Seu nome completo é Manoel Wenceslau Leite Barros. Pertence à geração moderna de 45 e destaca-se por uma linguagem inovadora repleta de neologismos. Segundo o próprio autor, seus poemas baseiam-se em suas experiências pessoais de vida.

O conteúdo temático do poema $O$ menino que carregava água na peneira referese ao fazer poético; de forma metafórica, associa-se a brincadeiras do cotidiano que o autor denomina como "peraltagens". O poema tem aproximação com o real, mas não o suficiente para situar-se em um contexto físico-real. Desse modo, o menino - diferente, conforme palavras da mãe - descobre que poderia brincar com as palavras e transformase em muitas personagens; sente-se livre para inventar por meio da linguagem. A mãe do menino, voz lírica do poema, não reprova as atitudes do menino, mas tenta interpretar suas ações e o percebe nesse mundo de fantasia e imaginação. Gomes (2009), ao desenvolver uma análise sobre esse poema, afirma que

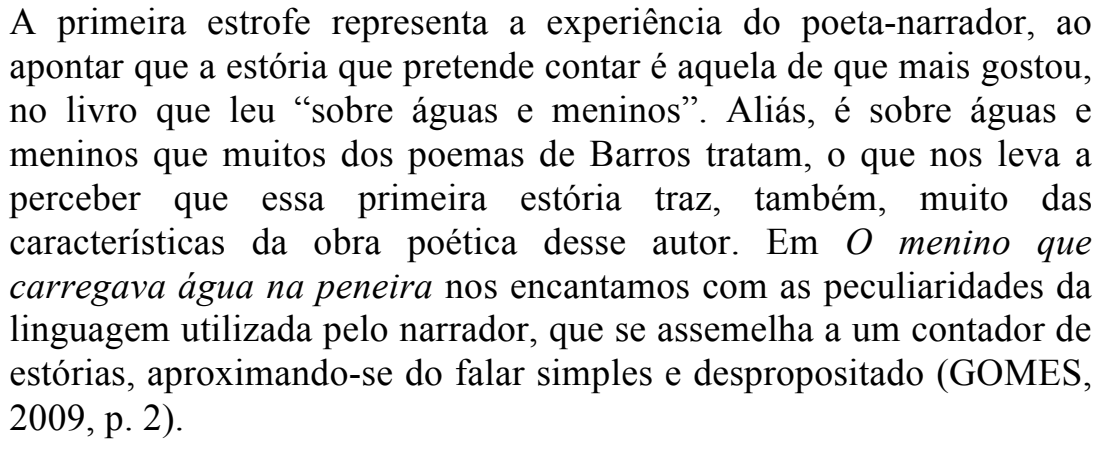

Compreendemos, então, que o poema, ao se dirigir ao público infantil, desenvolve um enredo autobiográfico situado no tempo e no espaço, o qual discorre sobre a imaginação do fazer poético que pode ser desafiador em qualquer etapa da existência e transformar-se em atividade lúdica.

\footnotetext{
${ }^{4}$ Disponível em http://www.fmb.org.br/ Acesso em 17/jun/2019
} 
O poema em estudo faz parte de do livro Exercícios de ser criança, publicado inicialmente em 1999, livro com que Manoel de Barros marcou sua estreia na literatura infantil. Em 2001, o poema foi inserido na coleção Literatura em minha casa, um projeto do Governo Federal de distribuição de livros aos alunos do Ensino Fundamental. A obra tem o nome de Palavras de encantamento e apresenta poemas de diversos escritores consagrados como Ferreira Gular, Elias José, Pedro Bandeira, Mario Quintana, entre outros. Por isso, consideramos que os interlocutores do poema são os alunos da segunda fase do Ensino Fundamental, mas também, pode estender-se aos alunos do primeiro ano do Ensino Médio.

Como defende Bakhtin/Volochínov (2009[1929]), o estilo associa-se ao enunciado e diz respeito às escolhas do autor com base na realidade permitida pelo gênero. Então, consideramos que o autor precisa ter domínio sobre o estilo do gênero, mas pode empregar, também, um estilo próprio, individual, uma vez que o poema é um gênero que permite essa individualidade, pois "aqui o estilo individual integra diretamente o próprio edifício do enunciado" (BAKHTIN, 2010[1979]), p. 265).

Nessa perspectiva, buscamos explorar com os alunos as escolhas lexicais, os neologismos, as figuras de linguagem, os efeitos sonoros de linguagem e a preocupação com a construção visual contidos no principal poema em estudo. Analisamos, com os alunos, as construções linguísticas, como as informações se organizam no texto e de que forma a situação extralinguística pode ser percebida nas escolhas desses elementos. Exploramos ainda, o estilo do autor e sua importância para a construção de sentido do texto.

Observamos que o estilo se evidencia na seleção lexical que compõe o poema, o que provoca um efeito de universalidade e de atemporalidade, no tom apreciativo sobre a infância, no uso da pontuação e pelo contraponto do discurso direto e indireto. De modo geral, o poema é composto por narrativas. As marcas da linguagem coloquial evidenciam-se no uso da conjugação perifrástica presente na fala da mãe (Você vai carregar...), o que também modaliza o texto.

A construção composicional configura-se como o acabamento do enunciado, envolve os elementos que mais conservam regularidades em textos do gênero. Ao explorarmos esses elementos, buscamos refletir sobre a disposição dos versos e estrofes, que recursos determinaram o ritmo, se a rima e a métrica tradicional se faziam presentes, entre outros.

Nesse caso, o poema não obedece a um esquema rígido de métrica e de versificação; observa-se, ao contrário, a liberdade comum dos poemas modernos. $\mathrm{O}$ ritmo também é um elemento subjetivo, moldado pela leveza da inocência.

Na próxima subseção, buscamos demonstrar nossas observações sobre como os elementos constitutivos do gênero - conteúdo temático, estilo e construção composicional - se configuram nos textos produzidos pelos alunos a partir desses estudos. Nossas reflexões foram norteadas por meio de um recorte de texto que direcionou nosso estudo de caso.

\subsection{As produções poéticas}

As atividades desenvolvidas com o gênero discursivo Poema culminaram em uma produção textual. Os alunos produziram seus poemas com temas selecionados por eles mesmos e criaram um Blog para a divulgação. Eram estudantes da primeira série do Ensino Médio de uma escola estadual situada em um município de seis mil habitantes, localizado no noroeste do Paraná. 
Foram produzidos 30 poemas, contudo, os próprios alunos realizaram uma votação para selecionar os 10 melhores que iriam compor o Blog Verso a verso. Partilhamos com os alunos nosso projeto de escrever um artigo sobre o trabalho realizado e requisitamos que nos ajudassem a escolher um poema para a análise. Os alunos elegeram o poema $A$ sabedoria não pode ser alienada, como o texto que melhor demonstrava seus conflitos adolescentes, tanto no que se refere à busca de conhecimentos quanto ao exercício da liberdade.

Embora reconheçamos que o planejamento que tínhamos para o trabalho com o gênero poema contemplava apenas a prática de leitura, por sugestão dos próprios alunos desenvolvemos, também, a prática escrita, o que possibilitou-nos verificar como o trabalho com a ordem metodológica se configurou na produção textual, pois "tornar a aula como acontecimento é eleger o fluxo do movimento como inspiração, rejeitando a permanência do mesmo e a fixidez mórbida no passado" (GERALDI, 2010, p. 100). Assim, um planejamento não pode ser inflexível e deve permitir que os "acontecimentos" transformem-se em possibilidades de aprendizagens.

$\mathrm{Na}$ sequência, apresentamos o texto selecionado para nosso estudo de caso:

\section{A sabedoria não pode ser alienada}

O que é sabedoria? O saber da vida?

A sabedoria pode mudar o mundo?

A cidade? A humanidade? A desigualdade?...

O saber nasce no mundo

Mas se no mundo continuar, no mundo morrerá!

Sabedoria,

Traz o fruto da vida.

Traz controle e equilíbrio,

Força e amor... Traz sorte na sorte...

Faz pensar que a Terra é um bom lugar!

Sabedoria,

$\mathrm{O}$ fruto da morte?

Traz maldade e intolerância

Descontrole e realidade... É a arma da morte!

É... a sabedoria ainda vai nos matar!

Sábio,

Todos podem ser sábios!

Aliás, um sábio não precisa muito falar...

Afinal, de que adianta falar?

Já que eles não vão acreditar...

É perigoso,

Perigoso é o falso sábio

Ele está na sua frente,

Não "do seu lado".

Consome a sua mente,

E te deixa ofuscado...

Evoluímos?

Será que seríamos capazes...

De descobrir o que nossos antepassados descobriram? 
Fazer o que eles fizeram?

Viver como eles viveram?

Tendo apenas o que eles tinham?

Será que a sabedoria evolui?

Ou apenas evoluiu?

É... se todos soubessem

A importância do saber,

Saberiam,

Que um sábio não sabe tudo,

Mas sabe o porquê

De não saber tudo...

E sabe o que fazer no mundo

Para ter um mundo melhor.

O texto constitui a primeira versão do poema, produzido logo após o trabalho especificado anteriormente. Está disposto em 42 versos, agrupados em 7 estrofes. Os versos são livres, ou seja, não obedecem a categorizações métricas, e possuem poucas construções rimadas. $\mathrm{O}$ aluno apresenta uma reflexão sobre a sabedoria a partir de sua vivência de adolescente, indagando como os saberes podem determinar a existência humana. O ritmo empregado caracteriza-se pela subjetividade do autor que se utiliza de muitas interrogações e reticências, o que demonstra que, mesmo obedecendo às fronteiras expostas pelo gênero, o aluno emprega um estilo peculiar, uma vez que no poema, "[...] o estilo individual integra diretamente o próprio edifício do enunciado, é um de seus objetivos principais" (BAKHTIN, 2010[1979], p. 265).

O autor desse texto aprecia estudos filosóficos e demonstra, por meio do poema, as angústias próprias de sua juventude. Suas preocupações existenciais aparecem no poema especialmente na segunda e terceira estrofes, quando apresenta aspectos positivos e negativos que podem ser ocasionados pela "sabedoria", tema do poema. Na quarta e quinta estrofes, o autor reflete sobre o sábio e o "falso sábio", apresentando uma opinião pessoal sobre essas personalidades. $\mathrm{Na}$ sexta estrofe, questiona ações contemporâneas em comparação com a evolução alcançada por gerações anteriores. E na última, exalta o domínio do conhecimento para a construção de um "mundo melhor". Além disso, o título sugere que existe uma falsa sabedoria (alienada), o que parece explicar a terceira e a quinta estrofes.

A produção escrita analisada, além de responder ativamente ao nosso procedimento didático com o gênero poema, dialoga com outras áreas de conhecimento, como a Filosofia, e revela o contexto extraverbal tanto de leituras extracurriculares do aluno quanto de suas próprias vivências cotidianas. Por exemplo, na segunda estrofe quando utiliza o recurso da intertextualidade com uma passagem bíblica (fruto da vida) deixa entrever um dos conflitos familiares vivenciados, pois pertence a uma tradicional família da classe média, que considera essencial a participação nas missas dominicais, enquanto o adolescente tende ao ateísmo e se recusa à participar do rito semanal o que gera discussões e desentendimentos familiares.

Com relação à composição, o texto é escrito em versos livres com poucas presenças de rimas (falar/acreditar; frente/mente). Não há preocupação com a métrica. O número de versos em cada estrofe oscila entre cinco e oito. As estrofes internas $\left(2^{\mathrm{a}}\right.$, $3^{\mathrm{a}}, 4^{\mathrm{a}}, 5^{\mathrm{a}}$ e $6^{\mathrm{a}}$ ) iniciam-se com uma ou duas palavras. Há uma preocupação com a construção visual do poema demonstrada na exposição de uma única palavra para iniciar as estrofes intermediárias, o que também se caracteriza como estilo do autor. Nessa direção, o trabalho com a construção composicional do gênero poema obtém 
resposta ativa nessa produção, pois o texto orienta-se pela estrutura "relativamente estável" (BAKTHIN, 2010[1979] dos enunciados explorados nas aulas. Observamos, então, que esse foi o elemento de mais fácil apreensão pelos alunos, pois no gênero do discurso "[...] a construção ou forma composicional é considerada como seu elemento mais característico" (GRILLO, 2010, p. 53) e, por isso, de fácil assimilação pelos alunos.

O estilo evidencia-se por meio de uma linguagem simples, próxima do coloquial e regada de questionamentos, algumas vezes compostos por apenas uma palavra (Evoluímos?). Há forte presença de sinais de pontuação com predomínio dos pontos de interrogação, de exclamação e de reticências, o que também evidencia o estilo do autor. O tempo verbal oscila entre o presente, o pretérito e o futuro, com destaque para o tempo futuro no fechamento de algumas estrofes (no mundo morrerá). Há, também, muitos verbos no infinitivo. O diálogo do eu-lírico do poema com o leitor evidencia-se pela presença de dêiticos (te deixa/sua frente). Ocorre, ainda, a presença de figuras de linguagem (Antítese - vida/morte; Metáfora - sabedoria... é a arma da mente), figuras de som (Aliteração - soubessem/saber/saberiam/sábio) entre outras.

Com relação a esse aspecto, o gênero discursivo poema permite a liberdade de expressão que foi criativamente utilizada pelo aluno. Nesse sentido, "há poetas que brincam com as palavras dum modo gostosíssimo de a criança ouvir e ler" (ABRAMOVICH, 2005, p. 66), e conseguem despertar diferentes tipos de emoção. Muitos autores de textos desse gênero exploram a ludicidade, "[...] vão juntando palavras, fazendo com que se movam pela página quase como uma cantiga, e ao mesmo tempo jogando com os significados diferentes que uma mesma palavra possui" (ABRAMOVICH, 2005, p. 66). Destarte, a liberdade de expressão é permitida por esse gênero literário, nesse sentido, o autor do poema em análise demonstrou apreender essa característica do gênero e a utilizou em seu projeto de dizer.

O poema demonstra-se em consonância com o trabalho desenvolvido, uma vez que apresenta os elementos constitutivos desse gênero, com marcas específicas da subjetividade do autor, o que indica que, apesar de obedecer às fronteiras, o autor não restringe seu projeto enunciativo, ao contrário, aproveita-se da liberdade concedida por esse gênero literário, desenvolve um estilo particular e dialoga com o seu interlocutor, o leitor do Blog Verso a Verso ${ }^{5}$. Constatamos, portanto, que os resultados apresentados pelos alunos são superiores ao que seria alcançado por um trabalho reduzido aos aspectos formais que não contemplasse as diversos configurações que norteiam a produção e circulação de um gênero discursivo, uma vez que "o texto é produto de um trabalho de escrita que não se faz seguindo regras predeterminadas. Todo texto pertence ao gênero que lhe fornece uma ossatura, mas o mero conhecimento da ossatura não leva à redação do texto em si” (GERALDI, 2010, p. 98).

O aluno demonstrou-se consciente da escrita como prática social, já que a tratou como uma situação real de interação e elaborou seu projeto discursivo visando aos interlocutores, ou seja, os leitores do Blog, com o intuito de incitar a produção de uma resposta. Compreendeu que o poema é um gênero literário que pode despertar emoções, provocar reflexões, dúvidas, incertezas e até mudanças de atitudes. Considerou o suporte de circulação investindo nos aspectos visuais, porém sem se dissuadir de apresentar seu projeto discursivo na integra.

Então, o trabalho com os aspectos discursivos do gênero desperta no aluno a consciência de que ao produzir seu enunciado está inserido em uma situação de interação e que deve considerar seus interlocutores, a esfera de produção e circulação, o

\footnotetext{
${ }^{5}$ https://versos7171.wordpress.com/
} 
contexto e os aspectos relativamente estáveis do gênero do discurso. Desse modo, o trabalho sistematizado com a linguagem cumpre seu papel e o aluno aprende a transitar com segurança nos diversos campos de atividade humana atuando ativamente nas práticas sociais.

\section{Considerações finais}

O poema analisado representa os textos produzidos por $90 \%$ dos alunos da turma e demonstra que o trabalho reflexivo desenvolvido com base na ordem metodológica (BAKHTIN/VOLOCHÍNOV, 2009[1929]) resultou em produções textuais escritas conscientes e bem elaboradas, nas quais se evidenciam a preocupação do autor com o interlocutor e com a esfera de circulação. Os poemas foram publicados no Blog Verso a Verso produzido e alimentado pelos próprios alunos, acreditamos que esse também tenha se constituído como um estímulo para as produções criativas e originais dos alunos.

Ao produzir o texto, o aluno construiu seu enunciado considerando os elementos constitutivos do gênero poema, uma vez que apreendeu os limites expostos pelo gênero; porém, sem perder a identidade de autor, por isso, utilizou as brechas para desenvolver um estilo individual.

Portanto, com base nos textos produzidos pelos alunos, afirmamos que um procedimento didático embasado nos estudos do Círculo de Bakhtin possibilita o trabalho pedagógico com a língua viva e dinâmica e uma compreensão real dos alunos sobre o uso da linguagem na sociedade.

\section{REFERÊNCIAS}

ABRAMOVICH, Fanny. Literatura infantil: gostosuras e bobices. São Paulo: Scipione, 1987.

BAKHTIN, Mikhail.; VOLOCHÍNOV, Valentin Nikolaevich. (1929). Marxismo e filosofia da linguagem. Tradução do francês por Michel Lahud e Yara F. Vieira. 13. ed. São Paulo: Hucitec, 2009.

BAKHTIN, Mikhail. (1979). Estética da criação verbal. Tradução de Paulo Bezerra. São Paulo: Martins Fontes, 2010.

BARROS, Manoel. O menino que carregava água na peneira. In: LEITE, Maristela Pertrili de Almeida. Palavras de encantamento: antologia de poetas brasileiros. São Paulo: Moderna, 2001. (Literatura em minha casa; V. 1)

BRAIT, Beth. Estilo. In. BRAIT, Beth (org.). Bakhtin: conceitos-chave. São Paulo: Contexto, 2013, p. 79-102.

CEREJA, Willian. Significação e tema. In: BRAIT, Beth (Org.). Bakhtin: ConceitosChave. São Paulo: Contexto, 2013. p. 201-220.

COSTA-HÜBES, Terezinha da Conceição. Os gêneros discursivos como instrumentos para o ensino de Língua Portuguesa: perscrutando o método sociológico bakhtiniano 
como ancoragem para um encaminhamento didático-pedagógico. In: NASCIMENTO, Elvira Lopes do; ROJO, Roxane Helena Rodrigues. (Orgs.). Gêneros de Texto/Discurso e os desafios da contemporaneidade: São Paulo: Pontes Editora, 2014. p. 13-34.

GERALDI, João Wanderley. A aula como acontecimento. São Carlos: Pedro \& João Editores, 2010.

GRILLO, Sheila V. de Camargo. Dialogismo e construção composicional em reportagens de divulgação científica de Pesquisa Fapesp. In: Paula, L. de; STAFUZZA Grenissa (Orgs.). Círculo de Bakhtin: Diálogos in possíveis. Campinas, SP: Mercado das Letras, 2010. p. 49-68.

GRILLO, Sheila V. de Camargo. Esfera e campo. In: BRAIT, B. (org.). Bakhtin: outros conceitos-chave. São Paulo: Contexto, 2014. p. 133 -160.

GOMES, Massillania Ferreira. Brincadeiras de meninos e meninas como "matéria de poesia" em Manoel de Barros. Disponível em: http:www.alb.com.br/anais14/Sem09/C09044.doc. Acesso em: 20 de jul. 2019.

LÜDKE, Menga; ANDRÉ, Marli E.D.A. Pesquisa em educação: abordagens qualitativas. 2. ed. Rio de Janeiro: E.P.U., 2014.

ROJO, Roxane. Materiais didáticos no ensino de língua. In: MOITA LOPES, Luiz Paulo da (Orgs.). Linguística Aplicada na modernidade recente. São Paulo: Parábola, 2013. p. 163-196.

MEDVIÉDEV, Pável Nikoláievitch. (1928). O método formal nos estudos literários: Introdução crítica a uma poética sociológica. Tradução: Ekaterina Vólkova Américo e Sheila Camargo Grillo. São Paulo: Contexto, 2012.

SOBRAL, Adail. Do dialogismo ao gênero: as bases do pensamento do Círculo de Bakhtin. Campinas, SP: Mercado das Letras, 2009.

VOLOCHÍNOV, Valentin Nikolaevich; BAKHTIN, Mikhail. Discurso na Vida e Discurso na Arte (sobre a poética sociológica).Trad. De Carlos Alberto Faraco \& Cristóvão Tezza [para fins didáticos]. Versão da língua inglesa de I. R. Titunik a partir do original russo, 1926.

VOLOCHÍNOV, Valentin Nikolaevich. (1930). A construção da enunciação e outros ensaios. Tradução de João Wanderley Geraldi. Supervisão da tradução: Valdemir Miotello. São Carlos: Pedro \& João Editores, 2013.

Como citar este trabalho:

Recebido em: julho de 2020. Aprovado em: setembro de 2020.

ORTEGA, L. R.; FILHO, M. N. dos R. S. A ordem metodológica do círculo de Bakhtin para o estudo da língua: uma análise do gênero poema. Traços de Linguagem. v. 4, n. 2, p. 37-50, 2020. 